\title{
Tumor Necrosis Factor Directs Allograft-Related Innate Responses and Its Neutralization Improves Hepatocyte Engraftment in Rats
}

\author{
Fadi Luc Jaber, ${ }^{* \dagger}$ Yogeshwar Sharma, ${ }^{* \dagger}$ Brandon G. Mui, ${ }^{*}$ Sorabh Kapoor, ${ }^{* \dagger}$ and Sanjeev Gupta ${ }^{* \dagger+\delta \Phi} \| * *$
}

From the Departments of Medicine ${ }^{*}$ and Pathology, ${ }^{\ddagger}$ the Marion Bessin Liver Research Center, ${ }^{\dagger}$ the Diabetes Center, ${ }^{\S}$ the Fleischer Institute for Diabetes and Metabolism, " the Irwin S. and Sylvia Chanin Institute for Cancer Research," and the Ruth L. and David S. Gottesman Institute for Stem Cell and Regenerative Medicine Research, ${ }^{* *}$ Albert Einstein College of Medicine, Bronx, New York

\author{
Accepted for publication \\ September 30, 2020. \\ Address correspondence to \\ Sanjeev Gupta, M.D., Albert \\ Einstein College of Medicine, \\ Ullmann Bldg., Room 625, \\ 1300 Morris Park Ave., Bronx, \\ NY 10461. E-mail: sanjeev. \\ gupta@ einsteinmed.org.
}

\begin{abstract}
The innate immune system plays a critical role in allograft rejection. Alloresponses involve numerous cytokines, chemokines, and receptors that cause tissue injury during rejection. To dissect these inflammatory mechanisms, we developed cell transplantation models in dipeptidylpeptidase-deficient F344 rats using mycophenolate mofetil and tacrolimus for partial lymphocyte-directed immunosuppression. Syngeneic hepatocytes engrafted in liver, whereas allogeneic hepatocytes were rejected but engrafted after immunosuppression. These transplants induced mRNAs for $>40$ to 50 cytokines, chemokines, and receptors. In allografts, innate cell type-related regulatory networks extended to granulocytes, monocytes, and macrophages. Activation of Tnfa and its receptors or major chemokine receptor-ligand subsets persisted in the long term. An examination of the contribution of Tnfa in allograft response revealed that it was prospectively antagonized by etanercept or thalidomide, which resolved cytokine, chemokine, and receptor cascades. In bioinformatics analysis of upstream regulator networks, the Cxcl8 pathway exhibited dominance despite immunosuppression. Significantly, Tnfa antagonism silenced the $C x c l 8$ pathway and decreased neutrophil and Kupffer cell recruitment, resulting in multifold greater engraftment of allogeneic hepatocytes and substantially increased liver repopulation in retrorsine/partial hepatectomy model. We conclude that Tnfa is a major driver for persistent innate immune responses after allogeneic cells. Neutralizing Tnfa should help in avoiding rejection and associated tissue injury in the allograft setting. (Am J Pathol 2021, 191: 79-89; https://doi.org/ 10.1016/j.ajpath.2020.09.014)
\end{abstract}

Allograft rejection hampers survival of transplanted organs, cells, and tissues. Although immunosuppressive drugs such as tacrolimus and mycophenolate mofetil, and corticosteroids allow allografts, drug adverse effects and acute-on-chronic or persistent low-grade rejection remain problematic. ${ }^{1,2}$ The innate responses mediated by $\mathrm{T}$, natural killer (NK), or other cell types and involvement of IFN-stimulated genes in allograft rejection is well-accepted. However, the critical drivers of tissue injury in allogeneic settings remain unclear. In acute allograft rejection, gene expression profiling of liver, heart, or kidneys consistently identifies as inflammatory characteristics and the overexpression of interferon (IFN)- $\gamma$, tumor necrosis factor (TNF)- $\alpha$, various ILs, chemokine receptors (CXCR3/CCR5), and their ligands. ${ }^{3}$ These inflammatory mediators are often produced in granulocytes, monocytes, and other innate cell types. Similarly, innate immune cells (such as monocytes) contribute to tissue injury in long-term allografts. ${ }^{2}$ Remarkably, gene expression profiling indicates that acute and chronic rejection share similarities in activation of IFN- $\gamma, \mathrm{TNF}-\alpha$, or other cytokines, chemokines, and receptors. $^{2,3}$ To control lymphocyte-dependent allograft

\footnotetext{
Supported by NIH grants R01-DK071111, R01-DK088561, P30DK41296, and P30 DK020541.

Disclosures: None declared.

Current address of Y.S., Homology Medicines, Bedford, MA; of S.K., Consultant Liver Transplant, Hepatobiliary-Pancreatic and Robotic Surgery, Zydus Hospitals and Healthcare, Ahmedabad, India.
} 
rejection, therapeutic targets include ILs (eg, IL-2, -4, -6, -12/ 23 , and -15$)^{1,4}$ and chemokines, ${ }^{5}$ whereas controlling innate responses needs additional strategies. ${ }^{6}$

Transplanting allogeneic cells or tissues is highly significant for liver-directed therapies. ${ }^{7-9}$ Because allogeneic hepatocytes are rapidly rejected, consistent with the role of $\mathrm{T}$ cells, ${ }^{10}$ and because tacrolimus and mycophenolate mofetil prevent the rejection, ${ }^{11}$ cell transplantation models offer opportunities for elucidating mechanisms in rejection. Although syngeneic hepatocytes engraft life-long in the liver, ${ }^{12}$ shortly after transplantation, most cells are cleared by ischemia-reperfusion events that involve vasoconstriction, endothelial injury, and inflammation through polymorphonuclear neutrophils (PMNs), macrophages [Kupffer cells (KCs)], or hepatic stellate cells (HSCs), producing cascades of cytokines, chemokines, and receptors. ${ }^{13-21}$ Importantly, syngeneic hepatocytes do not activate T, NK, or dendritic cells, ${ }^{14}$ thus offering distinctions in innate and acquired responses. Previously, hepatic mRNA expression analyses and assays for innate cell activations after syngeneic hepatocyte transplants with or without prior PMN or KC depletion established that TNF- $\alpha$, IL- 6 , and other cytokines or chemokines significantly contributed to cell clearance. ${ }^{15}$ The centrality of TNF- $\alpha$ after syngeneic cell transplantation-induced cytokine, chemokine, and receptor cascades was revealed by its neutralization with etanercept ${ }^{13}$ or by transcriptional down-regulation with thalidomide. ${ }^{16}$ However, the role of TNF- $\alpha$ in allografts is unknown.

To investigate the role of cytokines, chemokines, and receptors in allograft rejection, cell-transplantation models were deployed in rats that lacked dipeptidylpeptidase (DPP)-4 because histochemically, this enzyme readily localizes DPP-4-positive transplanted cells. ${ }^{11,16,22}$ In addition, preconditioning DPP-5-negative rats with the DNA-intercalating chemical retrorsine plus two-thirds partial hepatectomy $(\mathrm{PH})$ inhibits hepatic proliferation and provides convenient liver repopulation assays. ${ }^{23}$ Mycophenolate mofetil and tacrolimus were included to inhibit T-cell responses. Corticosteroids were avoided because they exert broad and less defined effects in immune and other cell types. Regulatory gene networks identified by functional genomics with targeted arrays for mRNA expression provided anticytokine interventions to better control rejection.

\section{Materials and Methods}

\section{Drugs and Reagents}

Tacrolimus (Astellas Pharma Inc., Tokyo, Japan), mycophenolate mofetil (Hoffman-La Roche, Basel, Switzerland), and etanercept (Amgen Inc., Thousand Oaks, CA) were obtained from a local pharmacy. These agents were suspended in normal saline. Thalidomide, retrorsine, and all chemicals were from Sigma-Aldrich Chemical Co. (St. Louis, MO). Thalidomide was dissolved to $25 \mathrm{mg} / \mathrm{mL}$ in dimethyl sulfoxide.

\section{Animals}

The Animal Care and Use Committee at Albert Einstein College of Medicine approved protocols in compliance with $\mathrm{NIH}$ and other regulations. Donor F344 rats 8 to 10 weeks old were from Charles River Laboratories (Wilmington, MA). Recipient DPP-4-negative F344 rats and donor Long-Evans Agouti (LEA) rats 8 to 10 weeks old were from the Liver Center Core (San Francisco, CA). Males and females were in equal numbers.

\section{Immunosuppression}

Tacrolimus, $2 \mathrm{mg} / \mathrm{kg}$, and mycophenolate mofetil, $100 \mathrm{mg} /$ $\mathrm{kg}$, were administered via gavage 16 to 20 hours before transplantation and then twice weekly for up to 3 weeks. The doses of etanercept, $9 \mathrm{mg} / \mathrm{kg}$ via tail vein, and thalidomide, $40 \mathrm{mg} / \mathrm{kg}$ intraperitoneally, ${ }^{13,16}$ were given 16 to 20 hours before transplantation and twice weekly afterwards in some studies. The controls received only vehicle.

\section{Cell Isolation and Transplantation}

Hepatocytes were isolated by collagenase or liberase perfusion as previously described. ${ }^{24}$ Isolated cells were $>80 \%$ viable by trypan blue dye and transplanted within 2 hours. For engraftment studies, $15 \times 10^{6}$ cells in $0.2 \mathrm{~mL}$ of RPMI 1640 medium were injected into the spleen during 10 seconds. For liver repopulation, rats preconditioned with 30 $\mathrm{mg} / \mathrm{kg}$ of retrorsine given intraperitoneally at 6 and 8 weeks of age were subjected 4 weeks later to $\mathrm{PH}$, and then $5 \times 10^{6}$ cells were intrasplenically transplanted after another week. For phagocytic activity in KCs, animals were given a 1-hour pulse of $0.1 \mathrm{~mL}$ of carbon intrasplenically, as previously described. ${ }^{15}$ Cell engraftment was analyzed 3 days and 1, 2, or 3 weeks after transplants. Liver repopulation was analyzed 3 weeks after transplants.

\section{Histochemical Staining}

Tissue samples were frozen in methylbutane to $-80^{\circ} \mathrm{C}$, and $5-\mu \mathrm{m}$ cryosections were prepared. Sections were fixed in ice-cold ethanol with hematoxylin and eosin staining for morphology and carbon-containing KCs. Myeloperoxidase activity in PMNs was stained with a kit (Sigma-Aldrich) as previously described. ${ }^{25}$ For CXCR2 localization, sections were fixed in $4 \%$ paraformaldehyde in phosphate-buffered saline, $\mathrm{pH} 7.4$, blocked with $3 \%$ goat serum in phosphatebuffered saline, $0.1 \%$ bovine serum albumin, and $0.1 \%$ Triton, and incubated with rabbit CXCR2 antibody (1:100, antibody 14935, Abcam, Cambridge, MA) overnight at $4^{\circ} \mathrm{C}$. Detection used goat anti-rabbit peroxidase-conjugated $\mathrm{IgG}$ (1:200, Sigma) with diaminobenzidine + (K3467, Dako Cytomation, Glostrup, Denmark). 


\section{Morphometric Measurements}

Carbon-containing $\mathrm{KCs}$, myeloperoxidase and PMNs, or CXCR2-positive cells were counted in high-power fields ( $\times 400$ magnification) with 25 consecutive liver lobules per tissue. Transplanted cells were counted in portal vein radicles and parenchyma in 25 to 50 liver lobules per animal. For liver repopulation, transplanted cell foci in 50 to 100 liver lobules were counted under $\times 100$ magnification. Cell numbers were counted in multiple microphotographs.

\section{Analysis of mRNA Expression}

Gene expression was analyzed in animals 6 hours, 3 days, or 1 and 2 weeks after cell transplantation $(n=3$ each). Total RNAs were isolated from liver samples by TRIzol Reagent (Life Sciences, Carlsbad, CA). One-microgram RNAs were converted to cDNA with a RT2 PCR Array First Strand Kit (SA Biosciences, Frederick, MD). RT-PCR used rat cytokine/chemokine/receptor arrays (PARN 011C; SA Biosciences) with probes for 84 genes, 5 housekeeping genes, 1 genomic DNA contamination control, 3 reverse transcription controls for cDNA conversion, and 3 other positive controls (Prism 7000 System; Applied Biosystems, Foster City, CA). The arrays were used according to instructions from the manufacturer. Fold expression differences were determined with the $2-{ }^{\Delta \Delta} \mathrm{Ct}$ method, as previously described. ${ }^{13,14,16,21}$ Experimental and control samples were individually normalized against invariant genes included in the arrays. Gene expression of twofold or greater up or down was considered significant. For ontologies and upstream regulator networks in gene expression datasets, we used Ingenuity Pathway Analysis (IPA) software 20.0 along with built-in tools (Qiagen, Germantown, MD), as previously described. ${ }^{26,27}$ The network analysis used prioritization based on $-\log (P$ value $)>1.3$ with $P<0.05$ using the Fisher exact test. The consistency scores, total regulator nodes, and downstream target numbers were noted in regulator networks.

\section{Study Design}

Cell engraftment was verified 6 hours, 3 days, and 1, 2, or 3 weeks after syngeneic (F344) or allogeneic (LEA) hepatocytes, respectively ( $n=3$ each), plus untreated controls $(n=3$; total $\mathrm{N}=36)$. Additional animals were included for immunosuppression with mycophenolate mofetil and tacrolimus $(n=6$ each; total $\mathrm{N}=30)$. Tissue necrosis, inflammation, and mRNA expression were examined. Next, TNF- $\alpha$ was neutralized by etanercept with or without mycophenolate mofetil and tacrolimus for liver repopulation in retrorsine/PH-preconditioned animals with allogeneic (LEA) cells $(n=6$ each; total $\mathrm{N}=12)$. Finally, effects of or thalidomide along with mycophenolate mofetil and tacrolimus on hepatic mRNAs and effector cells were studied in animals 6 hours after (LEA) hepatocytes ( $n=6$ each; total $\mathrm{N}=36$ ). The experiments included two to three repeats for reproducing major findings.

\section{Statistical Analysis}

Each experimental analysis used multiple rats. Data are given as means \pm SEM. Statistical significances were analyzed by $t$-test, $\chi^{2}$ test, or analysis of variance (ANOVA) by Bartlett's post hoc tests with GraphPad Prism software version 8.2.1 (GraphPad Software, San Diego, CA). For functional genomics analyses, built-in IPA tools were used with the Fisher exact test. $P<0.05$ was considered significant.

\section{Results}

After transplantation, syngeneic (F344) hepatocytes were observed in portal vein radicles at similar rates after 1 and 3 weeks ( $n=6$ each) (Figure 1). By contrast, although syngeneic cells engrafted in hepatic parenchyma, as seen in prior studies, their numbers declined at 1 to 3 weeks, indicating attrition during integration in liver plates. ${ }^{28}$ As expected, allogeneic hepatocytes from LEA rats were not observed after 7 days, and infiltrating lymphocytes appeared in portal areas during rejection. To modulate drug levels without diminishing their capacity to reject allogeneic hepatocytes, mycophenolate mofetil and tacrolimus were not given daily, which resulted in engraftment throughout the 3 -week period, although with ongoing clearance after 1 and 3 weeks from both vascular spaces and liver parenchyma versus syngeneic cells $(n=6$ each $)(P<0.05$, ANOVA).

\section{Profiling of Cytokine, Chemokine, and Receptor mRNAs Elicited Cell Type-Related Immune Responses}

Given the time-frames for cell engraftments, the tissue was examined at 6 hours and 3, 7, or 14 days after transplants ( $n=3$ each), which indicated substantial gene expression differences (Supplemental Table S1). After 6 hours, in syngeneic and allogeneic transplants versus healthy controls, $>80 \%$ differentially expressed genes were up-regulated twofold or greater ( $n=52$ and 43 , respectively) (Supplemental Figure S1, A-D). Several of these genes remained up-regulated for 14 days. Surprisingly, the magnitude and persistence of gene expression differences were greater for syngeneic as opposed to allogeneic transplants $(P<0.05)$. In allogeneic cells, gene expression primarily altered early (at 6 hours), in agreement with time to rejection. In allogeneic cells with mycophenolate mofetil and tacrolimus, more genes were down-regulated early (at 6 hours) and later (3, 7, or 14 days) versus those observed with either syngeneic or allogeneic transplants (Supplemental Figure S1, E and F).

To assess the consequences of gene expression differences between 6 hours and 14 days, we queried datasets with IPA 

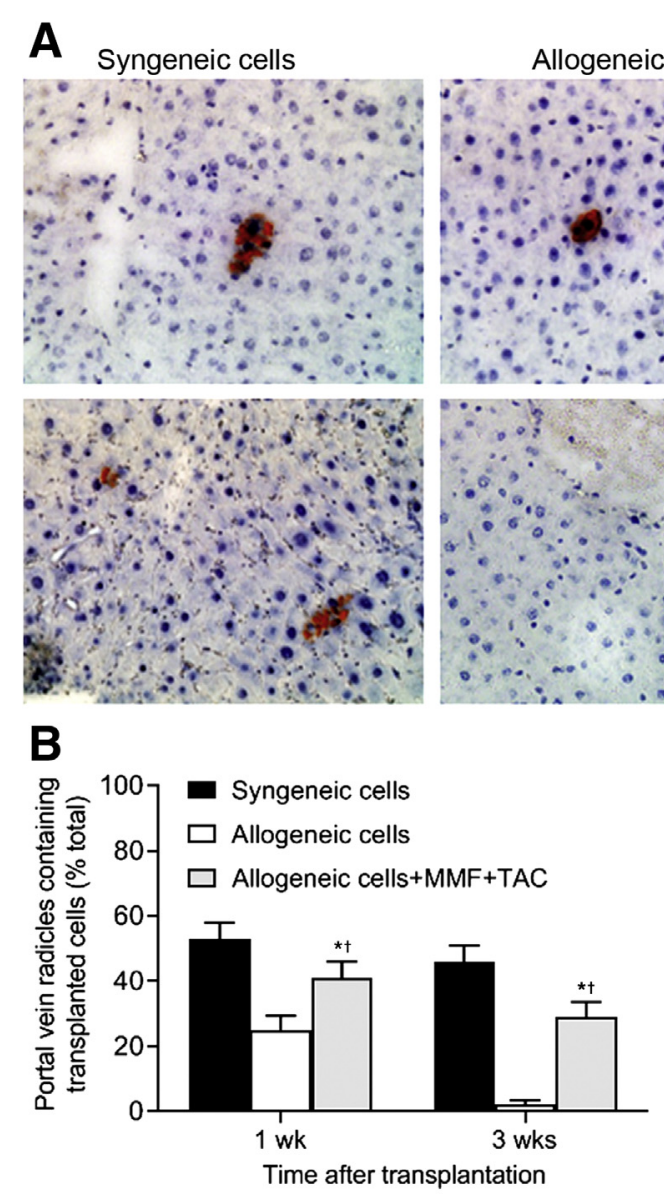

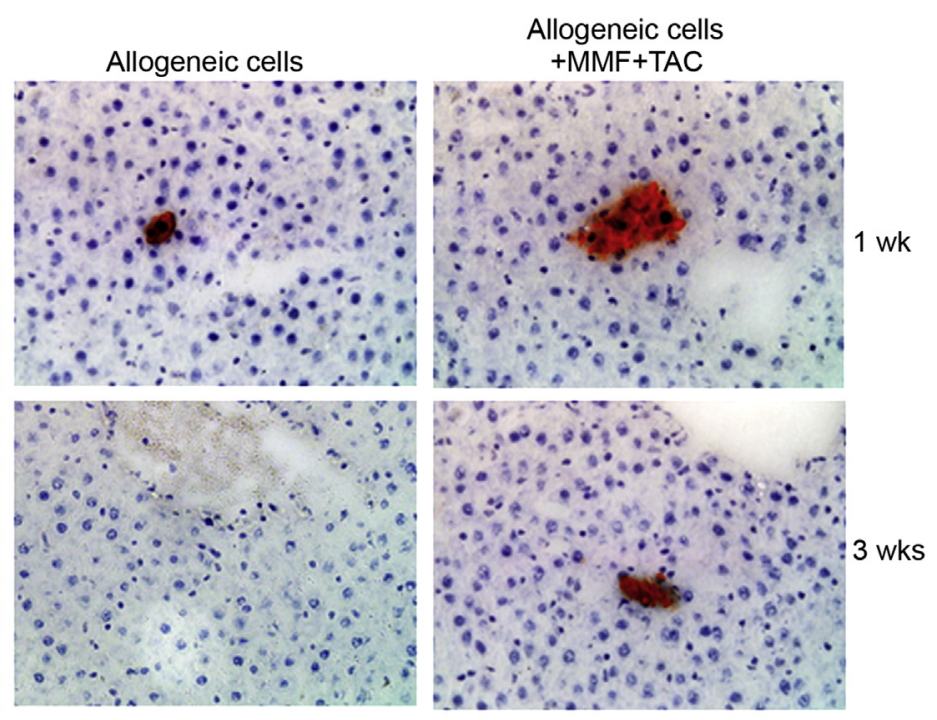

C

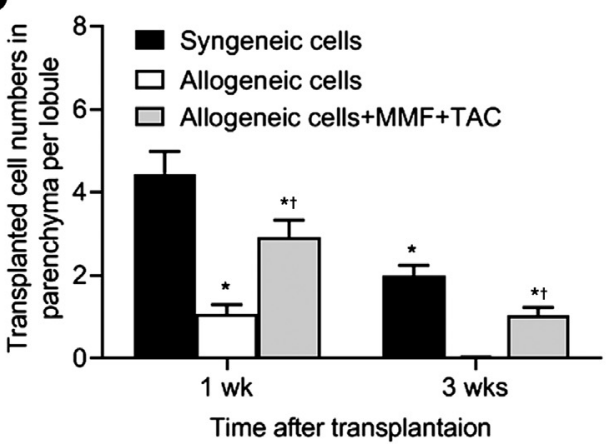

Figure 1 Engraftment of transplanted hepatocytes in dipeptidylpeptidase (DPP)-4-negative rats. A: Microphotographs indicating DPP-4-positive donor hepatocytes (red) after 1 week (top row) and 3 weeks (bottom row). B: Proportion of consecutive portal areas with transplanted cells. C: Number of transplanted cells per liver lobule. Syngeneic (F344) hepatocytes were not cleared from vascular spaces, although their numbers in liver parenchyma decreased between 1 and 3 weeks. Allogeneic (Long-Evans Agouti rats) cells were rejected after 1 week. This finding was ameliorated by mycophenolate mofetil (MMF) and tacrolimus (TAC), and transplanted cells survived for 3 weeks but with continuing clearance from vascular areas and parenchyma. Data are expressed as means \pm SEM (B and C). $n=6$ in each group (A). ${ }^{*} P<0.05$ versus syngeneic cells (ANOVA with Bartlett post hoc tests); ${ }^{\dagger} P<0.05$ versus allogeneic (ANOVA with Bartlett post hoc tests). Original magnification, $\times 400($ A).

by an unsupervised approach and examined top cytokine, chemokine, and receptor networks. The $-\log (P$ value $)$ threshold for network identification of $>1.3$ and false discovery rate of $<5 \%$ revealed the following active networks after 6 hours recruitment of blood cells in syngeneic cell recipients, activation of phagocytes in allogeneic cell recipients, and cell viability of leukocytes in recipients of allogeneic cells with mycophenolate mofetil and tacrolimus (Supplemental Figure S2, A-C). Overall, these networks in syngeneic, allogeneic, and allogeneic with mycophenolate mofetil and tacrolimus exhibited consistency scores of 4.4, 4.4 , and 57.3, total regulator nodes of 23,21 , and 21 , and total targets of 21,19 , and 8 , respectively. In case of syngeneic cells, angiotensinogen was the predominant regulator, supporting involvement of expected vascular events, ${ }^{29}$ whereas IL-18 (IFN- $\alpha$-inducing factor) was the predominant regulator in allografts, consistent with established acute alloresponses. $^{3}$ After mycophenolate mofetil and tacrolimus immunosuppression, most cytokines or chemokines were up-regulated, whereas regulator networks were mostly down- regulated and involved additional innate cell types, including granulocytes and others. The regulator networks further diverged subsequently. After 14 days, active networks in syngeneic transplants included abnormalities of knee joints, damage in kidney, levels of IL-6 in blood, and liver regeneration with a consistency score of 8.3, 23 total nodes, and 14 total targets (Supplemental Figure S2D). Thus, inflammatory and reparative processes induced by syngeneic cells continued for an unexpectedly long time, despite tissue morphology returning to normal within 3 days. After allogeneic cells, the networks concerned recruitment of dendritic cells and trafficking of lymphocytes, with a consistency score of 13.9, 22 total nodes, and 9 total targets that were largely in various states of inhibition (Supplemental Figure S2E). Because allografts were rejected before 14 days, this finding agreed with the anticipated T-cell-mediated rejection and subsidence of effector responses after transplanted cell clearances. In case of allogeneic cells treated with mycophenolate mofetil and tacrolimus, the network intersections were complex with activation or inhibition and a consistency 
score of $18.8,32$ total nodes, and 21 total targets (Supplemental Figure S2F). In aggregate, the processes included the following: chemotaxis of mononuclear cells, migration of dendritic cells, chemoattraction of leukocytes, and recruitment of macrophages. As cytokines, chemokines, and receptors typically orient these responses, ${ }^{6}$ we further examined these messenger molecules.

\section{Inflammation after Cell Transplantation Involves Chemokines and Tnfa}

To identify genes of interest after allograft rejection, differentially expressed genes early (6 hours) were compared to those expressed late (14 days). The Tnfa group in data sets comprised Tnf and its receptor (Tnfsfla; Abcfl), which increases Tnfexpression, and Sppl (alias osteopontin), which is involved in amplifying inflammation. The monocyte- or macrophage-related group included the effector chemokines Ccl25, Cxcl2, and Cx3cll (ligands for Ccr9, Cxcr2, and Cxcr3, respectively, affecting chemotaxis, T-cell activation, and endothelial adhesion) and the chemokine receptor $\mathrm{Ccrl}$ (which binds multiple CCL ligands to affect monocyte/ macrophage responses). The genes related to granulocytes, platelets, or B cells included Bcl6 (expansion of B-cells), Ccl11 (eosinophil chemotactic protein; ligand for Ccr3), Cxcl4 (platelet factor-4, released during platelet aggregation;
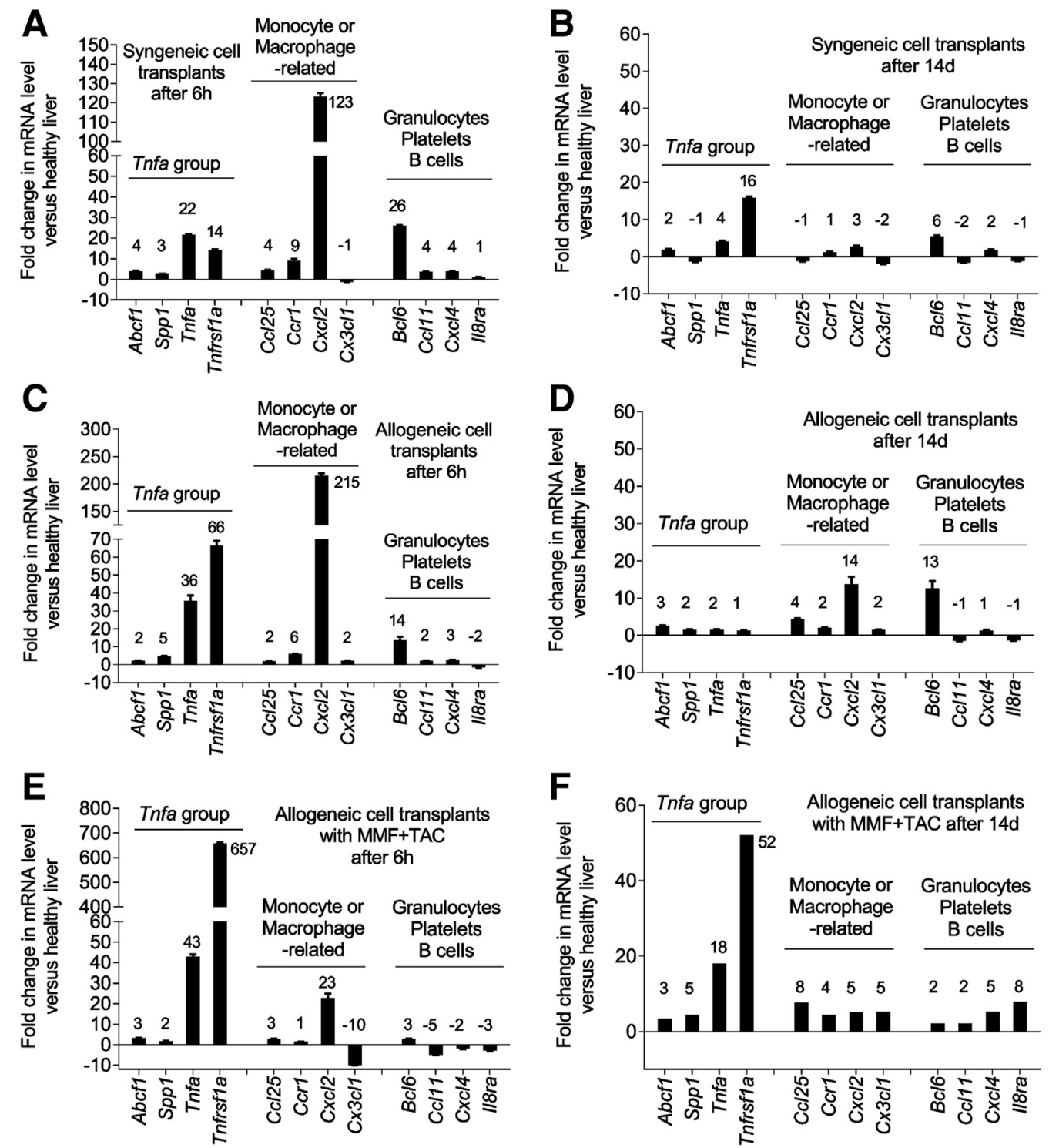

Figure 2 Grouped distribution of cytokines, chemokines, and receptors at early and late times after cells. Genes are grouped according to regulation of Tnfa expression or signaling in monocytes or macrophages and putative roles in expansion or inflammation mediated by B cells, granulocytes (polymorphonuclear neutrophils, eosinophils, and basophils), or platelets. Data are from 6 hours and 14 days after syngeneic cells (A and B), allogeneic cells (C and D), and allogeneic cells with mycophenolate mofetil (MMF) and tacrolimus (TAC) (E and F). Gene expression in fold versus healthy liver is indicated. Expression of Tnfa group was upregulated early with long-term persistence in cases of syngeneic and allogeneic cells with MMF+TAC. Data are expressed as means \pm SEM. 
ligand for $C x c r 3$ ), and Il8ra (alias Cxcrl, binds $C x c l-5,-6$, and -8 to affect granulocyte chemotaxis). ${ }^{6,30}$

Although the gene expression patterns were similar in cell transplant groups, some differences were also observed. The Tnfa group was activated after 6 hours in each group. Most activation was observed in allogeneic cells treated with mycophenolate mofetil and tacrolimus (Tnfa, 43-fold; Tnfsfla, 647-fold), followed by allogeneic cells without immunosuppression (Tnfa, 36-fold; Tnfsfla, 66-fold), and then by syngeneic cells (Tnfa, 22-fold; Tnfsfla, 14-fold) (Figure 2, A, C and E). Fourteen days after transplants, the Tnfa group essentially normalized in allograft recipients (Figure 2D); but remained up-regulated in syngeneic or allogeneic cells treated with mycophenolate mofetil and tacrolimus, especially the latter (Figure 2, B and F). The cytokines, chemokines, and receptors accompanying monocyte/macrophage group and those related to granulocytes, platelets, or B cells were activated 6 hours after syngeneic or allogeneic transplants with variable upregulation to 14 days. In allogeneic cells treated with mycophenolate mofetil and tacrolimus, activation of cytokines, chemokines, and receptors because of innate cell types became prominent at a later time point, after 14 days. The transducers in allograft rejection by innate responses involved Tnfa and related chemokines or receptors.

\section{Antagonism of Tnfa Improves Engraftment and Proliferation of Allogeneic Hepatocytes}

Previously, etanercept or thalidomide treatment before transplanting syngeneic hepatocytes was shown to normalize the cascade of cytokines, chemokines, and receptors within 6 hours. ${ }^{13,16}$ Therefore, this study examined this early time for mRNA expression in allografts after adding etanercept or thalidomide to the mycophenolate mofetil and tacrolimus regimen (Supplemental Table 2). Remarkably, cell transplantation-induced expression of cytokines, chemokines, and receptors was largely normalized by etanercept or thalidomide $(83 \%$ and $78 \%$, respectively; $P<0.05$, ANOVA) (Figure 3A). Those at abovenormal levels were Tnfa (10- and 16-fold, respectively) and its receptor Tnfsfla (327- and 149-fold, respectively) and $\mathrm{Cxcl} 2$ (twofold and threefold, respectively) after etanercept and thalidomide treatment, and $A b c f l$ (twofold) after thalidomide treatment (Figure 3B). Gene networks were mapped by IPA to investigate the regulatory significance of these differences (Supplemental Figure S3A). In allogeneic controls treated with mycophenolate mofetil and tacrolimus, the top network was $\mathrm{Cxcl}$ (or $\mathrm{Il}$ ), a cytokine that engages Cxcr 1 and $C x c r 2$ (that also binds $C x c l 2$ ), with several active downstream regulators. ${ }^{30}$ The major functions of $\mathrm{Cxcl} 8$
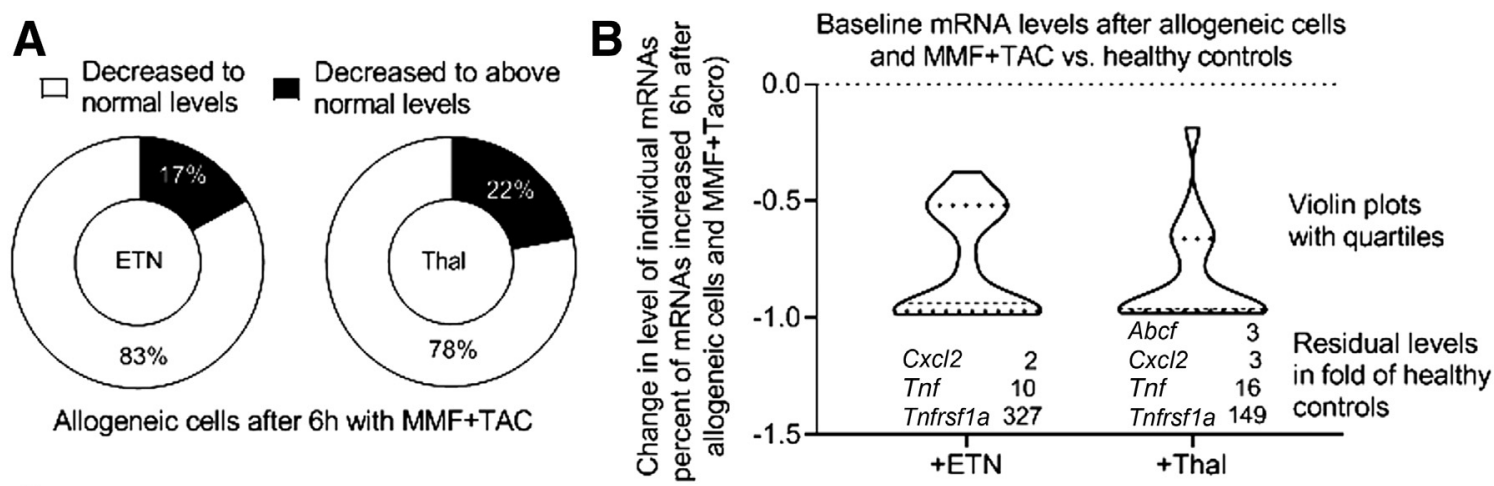

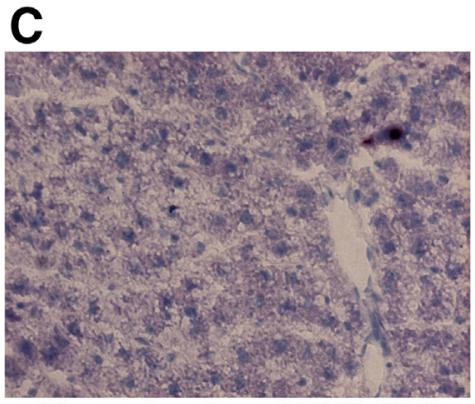

Allogeneic cells and MMF+TAC

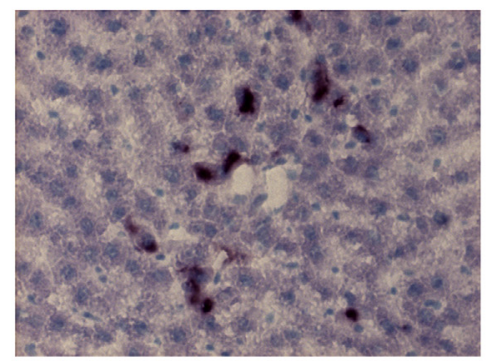

Allogeneic cells and MMF+TAC+Thal

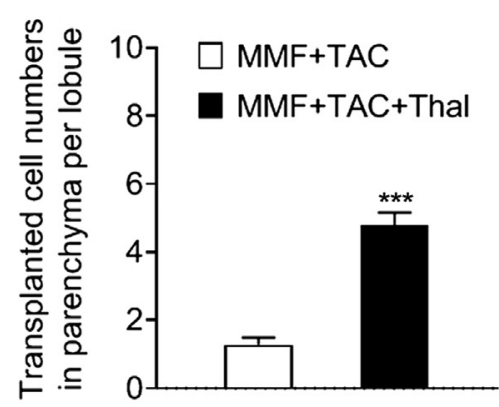

Figure 3 Regulation by etanercept (ETN) and thalidomide (Thal) of cytokines, chemokines, and receptors affected within 6 hours by allogeneic cells with mycophenolate mofetil (MMF) and tacrolimus (TAC). A: The proportion of genes returning to normal or lower expression levels was significantly different after adding ETN or Thal to MMF+TAC regimen. B: Violin plots for gene expression after ETN or Thal, including quartile distributions, and levels of residual upregulated genes versus healthy controls. The dotted black line at the top indicates baseline mRNA levels after allogeneic transplants with MMF $+\mathrm{TAC}$ versus healthy controls. The differences were significant for both ETN and Thal. C: Engraftment of allogeneic hepatocytes after adding Thal to MMF+TAC increased by severalfold, as indicated by DPP-4 histochemistry (red) and morphometric quantitation of donor cells in the liver). Data are expressed as means \pm SEM (C). $n=3$ biological replicates in each group (A and $\mathbf{B}) ; n=6$ (C). ${ }^{* * *} P<0.001$ versus MMF+TAC (t-test). Original magnification, $\times 400$ (C). 

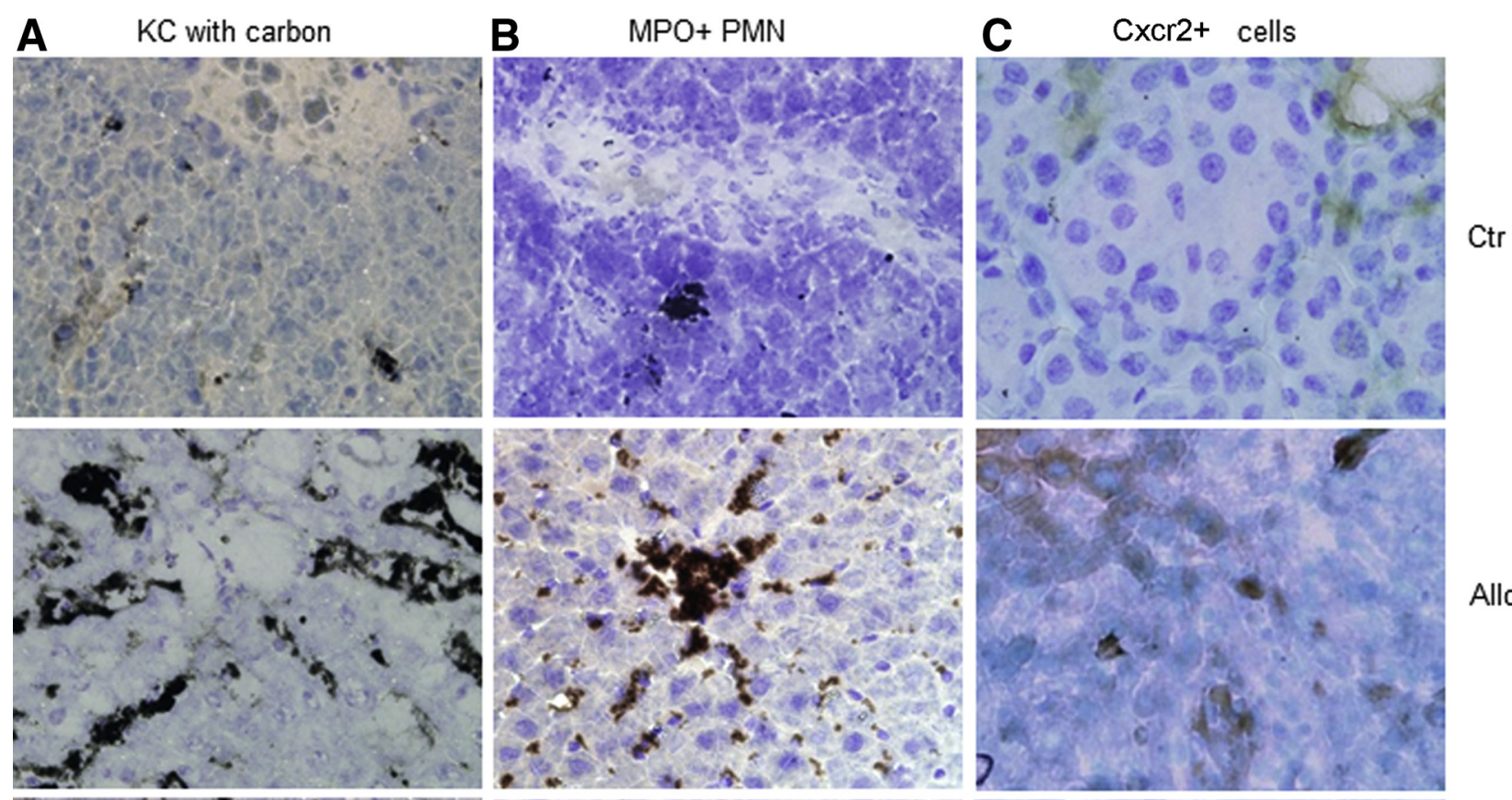

Allo
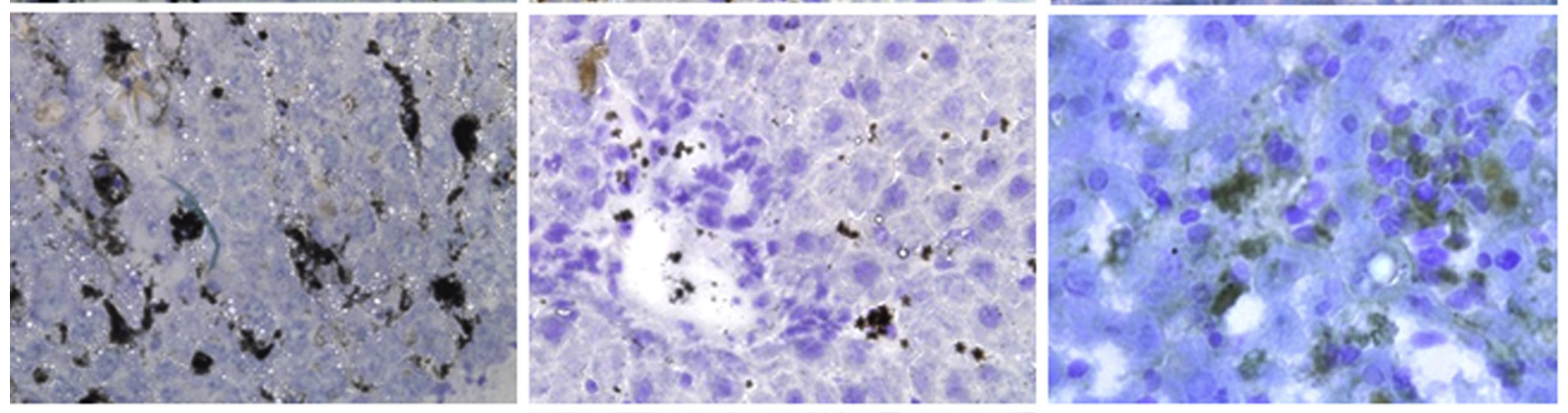

Allo

MMF

+TAC
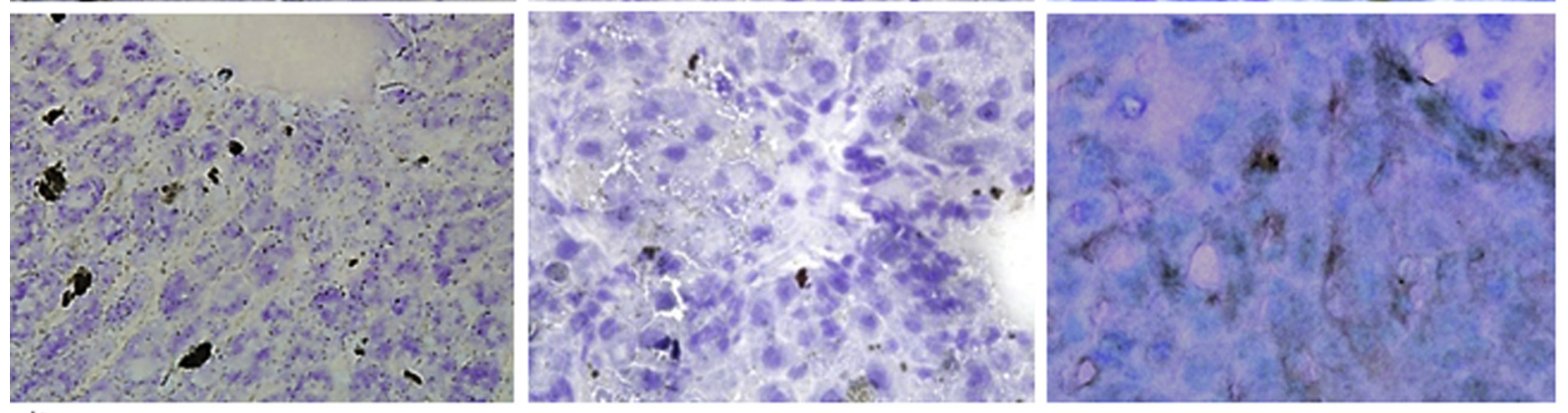

Allo

MMF

+ TAC

+ ETN
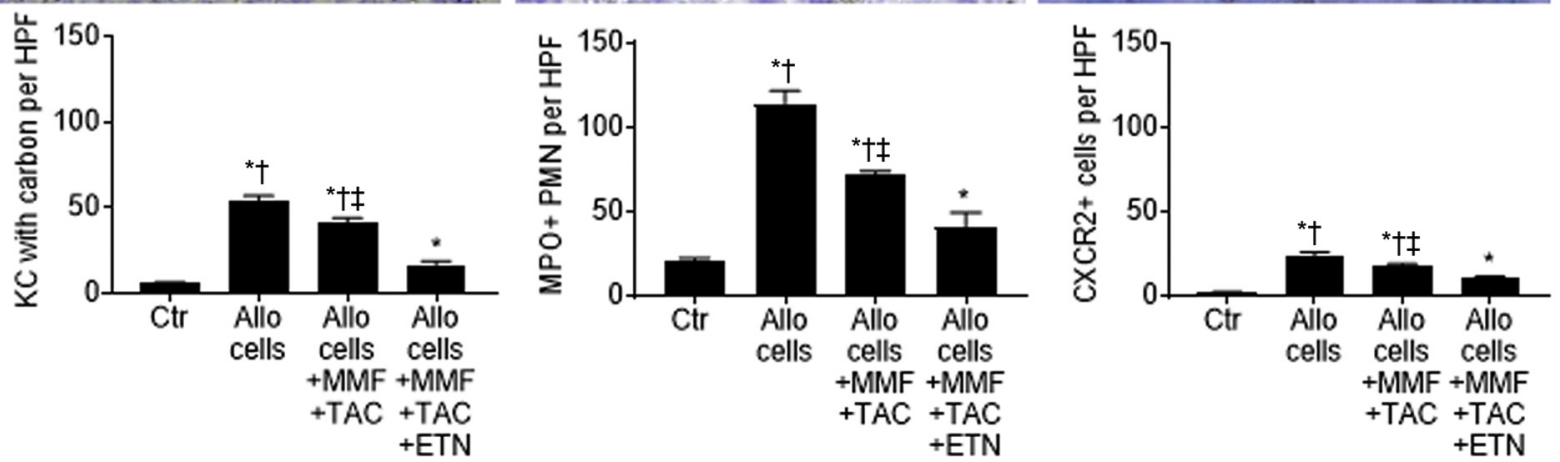

Figure 4 Effector cell responses 6 hours after allogeneic cell transplants with or without mycophenolate mofetil (MMF), tacrolimus (TAC), and/or etanercept (ETN). Analysis of Kupffer cell (KC) activation with carbon uptake (A), appearance of myeloperoxidase (MP0) and polymorphonuclear neutrophils (PMNs) (B), and prevalence of $\mathrm{Cxcr2}$ expression in infiltrating or parenchymal liver cells (C). Charts at the bottom provide morphometric analysis from multiple animals per condition. Allogeneic cells with or without MMF+TAC rapidly induced phagocytosis in $\mathrm{KCS}$, along with accumulation of PMN and $\mathrm{CxCr2}$ expression in infiltrating or parenchymal cells. Each of these processes decreased after ETN was added to MMF+TAC. ${ }^{*} P<0.05$ versus controls (ANOVA with Bartlett tests); ${ }^{\dagger} P<0.05$ versus Allo+MMF+TAC+ETN (ANOVA with Bartlett tests); and ${ }^{\ddagger} P<0.05$ versus Allo alone (ANOVA with Bartlett tests). Data are expressed as means \pm SEM. $n=3$ in each group. Original magnification, $\times 400($ A-C). HPF, high-power field. 
include induction of chemotaxis in PMNs or other granulocytes and that of phagocytosis in macrophages. Remarkably, after etanercept or thalidomide treatment, the Cxcl8 network was silenced and various downstream regulators were inhibited (Supplemental Figure S3, B and C). To further substantiate the benefit of prior TNF- $\alpha$ antagonism for allografts, recipients with immunosuppression with or without thalidomide were studied $(n=6)$ (Figure 3C). The cell engraftment after thalidomide was threefold to fourfold greater throughout the 2-week study after transplantation $(P<0.0001, t$-test $)$.

$\mathrm{KC}$ activity with carbon phagocytosis (Figure 4A) was examined to validate the contribution of early innate responses of TNF- $\alpha$ and Cxcl8 after cell transplantation ( $n=6$ each) (6 hours). In allogeneic cells with or without mycophenolate mofetil and tacrolimus treatment, carboncontaining KCs increased versus healthy controls by $9- \pm$ 1-fold and 7- \pm 1-fold, respectively, whereas after mycophenolate mofetil, tacrolimus, and etanercept treatment, the increased reduced to $3- \pm 1$-fold $(P<0.05$, ANOVA). Similarly, myeloperoxidase and PMNs increased in allogeneic cells with or without mycophenolate mofetil and TAC versus healthy controls by $6- \pm 0.4$-fold and $4- \pm$ 0 .1-fold, respectively, but after mycophenolate mofetil, tacrolimus, and etanercept treatment, this increase attenuated to $2- \pm 0.1$-fold $(P<0.05$, ANOVA) (Figure 4B). The Cxcr2-positive infiltrating or parenchymal cells in allotransplants with or without mycophenolate mofetil and tacrolimus versus healthy controls increased 11- \pm 1 -fold and 8- \pm 0.1 -fold, respectively, and after mycophenolate mofetil, tacrolimus, and etanercept treatment, the increase was 5- \pm 0.7 -fold $(P<0.05$, ANOVA) (Figure $4 \mathrm{C})$. This re-emphasized the key role of TNF- $\alpha$ as a driver of innate responses in allograft rejection.

For further loss-of-function studies, TNF- $\alpha$ was neutralized by etanercept before and after cell transplantation with twice per week dosing because drug half-life in rats is 46 to 77 hours. $^{13}$ In a retrorsine/PH liver repopulation model (Figure 5A), transplanted hepatocytes, including allogeneic ones, linearly proliferate during the initial few weeks. ${ }^{11}$ Allogeneic (LEA) hepatocytes engrafted in liver treated with mycophenolate mofetil and tacrolimus throughout the

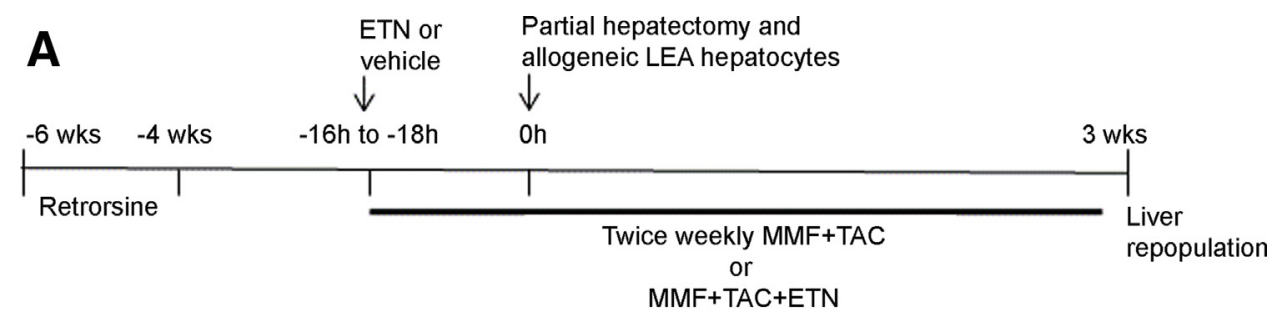

B
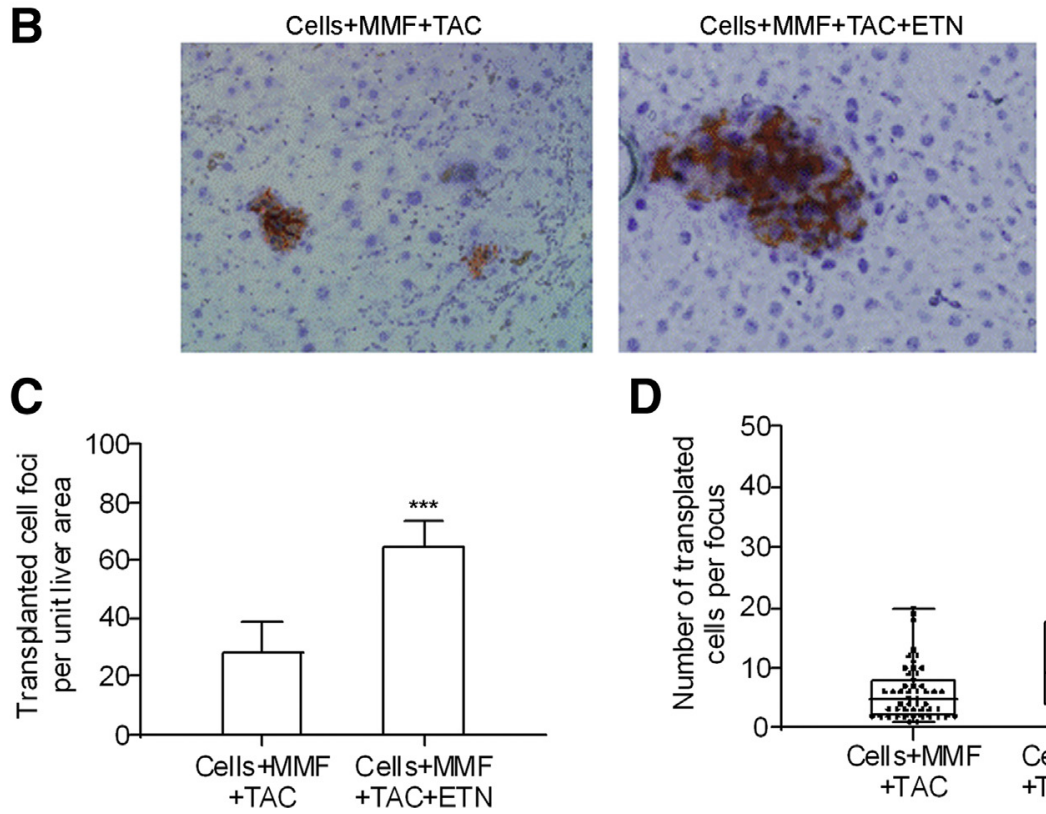

D

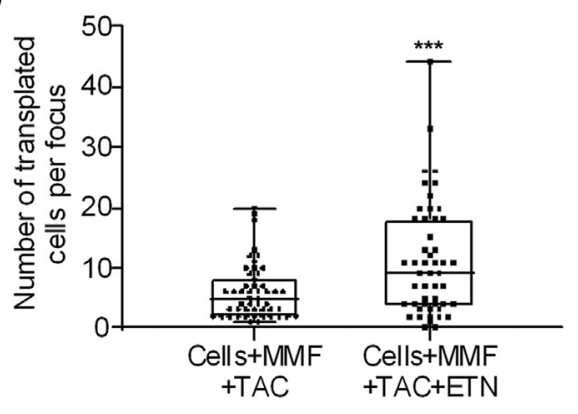

Figure 5 Effect of neutralizing Tnfa by etanercept (ETN) on cell engraftment and proliferation. A: Schematic of the timeline for preconditioning of dipeptidylpeptidase (DPP)-4-negative rats with retrorsine/partial hepatectomy (PH) followed by ETN or vehicle and then transplantation of allogeneic hepatocytes. Twice-weekly mycophenolate mofetil (MMF) and tacrolimus (TAC) without or with etanercept (ETN) were followed by animal sacrifice 3 weeks after cells for assays. B: Representative foci containing transplanted DPP-4-positive hepatocytes (red) after 3 weeks. C and D: Morphometry for transplanted cell foci per high-power field (C) and transplanted cell numbers in individual focus (D). Adding ETN to MMF+TAC increased cell engraftment and proliferation kinetics by more than twofold. Data are expressed as means $\pm \operatorname{SEM}(\mathbf{C}$ and $\mathbf{D}) . n=6$ in each group. ${ }^{* * *} P<0.001$ versus cells + MMF + TAC ( $t$-tests). Original magnification, $\times 200$ (B). LEA, Long-Evans Agouti. 
3 -week study period $(n=6)$. In animals with mycophenolate mofetil, tacrolimus, and etanercept, transplanted cells engrafting as discrete DPP-4-positive cell foci increased by 2.2-fold versus mycophenolate mofetil and tacrolimus [ $65 \pm 8$ and $29 \pm 11$ per 10 high-power fields, respectively; $n$ $=50$ areas each ( $n=6$ each), $P<0.05, t$-test] (Figure 5B). Transplanted cells proliferated less than reported in prior studies, probably because of partial immunosuppression with the mycophenolate mofetil and tacrolimus regimen. ${ }^{11}$ Nonetheless, individual foci contained significantly more transplanted cells with mycophenolate mofetil, tacrolimus, and etanercept versus those with mycophenolate mofetil and TAC $(n=6$ each $)(P<0.05$, Mann-Whitney test $)$ (Figure 5C). The top quartile with largest foci in recipients of mycophenolate mofetil, tacrolimus, and etanercept exhibited 2.3-fold more transplanted cells $(P<0.05)$ (Figure 5D). This emphasized that TNF- $\alpha$ actively interfered in engraftment and proliferation of allografted cells.

\section{Discussion}

The current studies reveal major roles for cytokines, chemokines, and receptors in allograft rejection. Remarkably, despite relatively few gene probes in mRNA expression arrays, they were sufficient for identifying critical cellular events and processes that were noted previously during short-term or long-term rejection in entire transcriptome analyses. ${ }^{2,3}$ In addition, differences in tissue inflammation following syngeneic and allogeneic cells, as well as modifications with mycophenolate mofetil and tacrolimus immunosuppression, were readily apparent. This finding likely reflects the major contribution in allograft rejection of relatively few cytokines, chemokines, and receptors. The resultant demonstration of TNF- $\alpha$-related inflammation in allografts is highly significant, in particular because its antagonism rebalanced expression of multiple associated cytokines, chemokines, and receptors to improve outcomes. The downstream effects or regulator networks were noteworthy for candidate innate immune cells (ie, PMNs and $\mathrm{KCs})$. This finding provides validation for the experimental allograft approach using cell transplantation models.

The gene expression signatures of early and persistent inflammatory cell recruitments (eg, monocyte/macrophages (KCs), PMNs, and others) add mechanistic detail. Syngeneic cells that elicit innate responses and allogeneic cells that induce further accretive responses identified regulatory effects in gene networks of Tnfa and related chemokines and receptors. mRNA expression in whole tissues was similar to that reported in previous human allograft studies. ${ }^{2,3}$ Importantly, this whole tissue approach avoids confounding from cell isolation-related artifacts. Remarkably, TNF$\alpha$ antagonism by etanercept and thalidomide controlled activation of chemokines and receptors, upstream regulator networks, and effector responses. Consequently, TNF- $\alpha$ antagonism improved engraftment and proliferation of allogeneic cells to syngeneic cell levels. ${ }^{13,16}$ Not only will this finding be significant for transplanting allogeneic cells, tissues and organs, it will also help in the interpretation of the pathology of tissue injury in long-term rejection. ${ }^{2}$ From this study, gene expression datasets suggest a role of TNFrelated cytokines, although prospective studies of this mechanism will be helpful.

The syngeneic and allogeneic hepatocyte transplant models with or without immunosuppression allowed the dissection of the roles of cytokines, chemokines, and receptors in rejection. Although prolonged hepatic inflammation after syngeneic cell transplants was previously noted with activation of $\mathrm{KCs}$ and inhibition of hepatobiliary transporter activity, ${ }^{31,32}$ persistent overexpression of Tnfa and other chemokines and receptors in these studies remains surprising. The ability to reverse these negative inflammatory responses in hepatic functions by anti-inflammatory drugs (eg, prostaglandin-endoperoxide synthase inhibitors, naproxen, or celecoxib), which also provide hepatoprotection by improving transplanted cell engraftment, ${ }^{21,32}$ offers suitable means to augment TNF- $\alpha$ inhibition in the transplant setting.

The hepatocyte allograft models reproduced short-term rejection observed in solid organs (liver, heart, and kidneys) with activation of $I F N G$ and $I F N G$-stimulated genes, which are amplified by TNF- $\alpha$ and chemokine receptors, such as CCR5 (through CCL3, CCL4, and CCL5) or CXCR3 (through CXCL4, CXCL9, CXCL10, or CXCL 11), to foster $\mathrm{T}$ and T-regulatory subset recruitments. ${ }^{2,3,6}$ These regulator responses were reproduced with fidelity in gene networks presented by differentially expressed cytokines, chemokines, and receptors. On the other hand, interventions based on interruption of selected chemokines alone are of unclear significance for allograft rejection. For instance, blocking CXCR3 in cardiac allograft recipients did not improve outcomes in one study, ${ }^{33}$ even though IFN- $\gamma$-producing effector cells decreased and improved allograft survival in another study. ${ }^{34}$ Because numerous chemokines and receptors are expressed despite immunosuppression in allogeneic transplants, difficulties in separating their individual significances are inevitable because of i) overlaps in ligandreceptor interactions; ii) lack of clarity in regulation of effector cell activities; iii) uncertainties in regulation of other injurious or protective cytokines, chemokines, and receptors; and iv) unknown effects in most cases of chemokines or receptors on rejection outcomes.

In this study, the functional genomics approach to characterize networks with IPA offered informative portraits of regulators in transplant conditions, including for liver regeneration (after syngeneic cells) or cellular nature of inflammation (after allogeneic cells with or without mycophenolate mofetil and tacrolimus). Previously, gene expression analysis with microarrays in human allografts identified TNFA as a key gene in short-term rejection ${ }^{35,36}$ and chronic hepatic injury. ${ }^{2}$ Through TNF- $\alpha$ signaling, activation of NF- $\kappa$ B network in human allografts,, 37 along 
with potential contributions of NF- $\kappa \mathrm{B}$ essential modulator or receptor-interacting protein kinases, should be significant for cell apoptosis or necroptosis. ${ }^{38}$ The NF- $\kappa \mathrm{B}$ signaling conjoins cell survival and apoptosis (eg, after ischemic preconditioning), although DNA damage in this setting may inhibit hepatic proliferation. ${ }^{39}$

The prominence of $T n f a$ among persistently up-regulated cytokines, chemokines, and receptor genes following allografts with mycophenolate mofetil and tacrolimus treatment points to macrophages (KCs) and granulocytes (PMNs) as effector types, although this role in the latter is generally less recognized. The PMNs and $\mathrm{KCs}$ efficiently express TNF- $\alpha$ and chemokines and receptors, ${ }^{6,15}$ including Ccl11, Ccl25, Cxcl2, Cxcl4, Cx3cl1 (ligands for Cccr3, Ccr9, Cxcr2, Cxcr4, and Cx3cr1, respectively), and Ccr1, which binds $\mathrm{Ccl} 3$, Ccl-4, and $\mathrm{Ccl}-5$, as well as the IL-8 receptor agonist (or Cxcr1) with ligands of $\mathrm{Cxcl} 1$ and $\mathrm{Cxcl} 2$ sharing 90\% sequence identity and $\mathrm{Cxcl8}$ (also known asIL-8). ${ }^{30}$ These ligand-receptor interactions are significant individually and together for chemotaxis, migration, adhesion, and activation of effector cells. ${ }^{6,30}$

Despite redundancies conferred by the overlapping nature of chemokine activities in cells, blocking specific chemokines or receptors is of interest for allografts. For instance, an antagonist of Ccxl8, the topmost active upstream regulator network in allogeneic cells treated with mycophenolate mofetil and tacrolimus, decreases acute injury in the rat renal allograft model. ${ }^{40}$ The rejection of pancreatic islet allografts in a murine model decreases with less PMN activation after blocking Cxcr1/2 with reparixin (alias repertaxin). ${ }^{41}$ In addition, repertaxin decreases PMN activation and improves engraftment of syngeneic hepatocytes. ${ }^{16}$ Similarly, blocking Cxcr4, along with simultaneous mycophenolate mofetil, decreases vascular injury and shortterm rejection in cardiac allografts. ${ }^{42}$ This finding is relevant for hepatic grafts because Cxcl4 (ligand for Cxcr4) is persistently expressed in allogeneic hepatocytes with mycophenolate mofetil and tacrolimus treatment. More recently, sustained Ccl22 release was shown to recruit Tregulatory cells in rodents to improve tolerance of allogeneic vascularized grafts. ${ }^{5}$

In conclusion, the extraordinary suppression of cytokines, chemokines, and receptors after TNF- $\alpha$ neutralization portends its potential in allograft setting. In one study, TNF- $\alpha$ blockade decreased alloantibody formation and inflammatory cells to increase graft survival in rat cardiac allograft and xenograft models. ${ }^{43}$ Similarly, in late-onset allograft rejection in patients, TNF- $\alpha$ neutralization by infliximab controlled orthoclone-muromonab-CD3 or corticosteroidresistant intestinal allograft rejection. ${ }^{44}$ Whereas TNF- $\alpha$ blockade may increase susceptibility to infections, it is better tolerated in people undergoing transplantation of liver versus other organs. ${ }^{45}$ Improving outcomes in allografts with thalidomide is another possibility because this drug has additional immunomodulatory properties and prevents vasculopathy after aortic allografts in rats. ${ }^{46}$ Finally, TNF- $\alpha$ inhibition offers new directions for combating tissue injury in long-term rejection, which is another unmet need.

\section{Acknowledgments}

We thank Chaoying Zhang and Gertrude Ukpong for providing technical assistance.

\section{Supplemental Data}

Supplemental material for this article can be found at http://doi.org/10.1016/j.ajpath.2020.09.014.

\section{References}

1. Szczepanik A, Iasella CJ, McDyer JF, Ensor CR: Cytokine-targeted therapy for the management of solid organ transplant recipients. Hum Immunol 2019, 80:184-190

2. Feng S, Bucuvalas JC, Demetris AJ, Burrell BE, Spain KM, Kanaparthi S, Magee JC, Ikle D, Lesniak A, Lozano JJ, Alonso EM, Bray RA, Bridges NE, Doo E, Gebel HM, Gupta NA, Himes RW, Jackson AM, Lobritto SJ, Mazariegos GV, Ng VL, Rand EB, Sherker AH, Sundaram S, Turmelle YP, Sanchez-Fueyo A: Evidence of chronic allograft injury in liver biopsies from long-term pediatric recipients of liver transplants. Gastroenterology 2018, 155: 1838-1851.e7

3. Spivey TL, Uccellini L, Ascierto ML, Zoppoli G, De Giorgi V, Delogu LG, Engle AM, Thomas JM, Wang E, Marincola FM, Bedognetti D: Gene expression profiling in acute allograft rejection: challenging the immunologic constant of rejection hypothesis. J Tran Med 2011, 9:174

4. Sandal S, Bae S, McAdams-DeMarco M, Massie AB, Lentine KL, Cantarovich M, Segev DL: Induction immunosuppression agents as risk factors for incident cardiovascular events and mortality after kidney transplantation. Am J Transplant 2019, 19:1150-1159

5. Fisher JD, Zhang W, Balmert SC, Aral AM, Acharya AP, Kulahci Y, Li J, Turnquist HR, Thomson AW, Solari MG, Gorantla VS, Little SR: In situ recruitment of regulatory $\mathrm{T}$ cells promotes donorspecific tolerance in vascularized composite allotransplantation. Sci Adv 2020, 6:eaax8429

6. Hughes CE, Nibbs RJB: A guide to chemokines and their receptors FEBS J 2018, 285:2944-2971

7. Forbes SJ, Gupta S, Dhawan A: Cell therapy for liver disease: from liver transplantation to cell factory. J Hepatol 2015, 62:S157-S169

8. Kakabadze Z, Kakabadze A, Chakhunashvili D, Karalashvili L, Berishvili E, Sharma Y, Gupta S: Decellularized human placenta supports hepatic tissue and allows rescue in acute liver failure. Hepatology 2018, 67:1956-1969

9. Kakabadze Z, Karalashvili L, Chakhunashvili D, Havlioglu N, Janelidze M, Kakabadze A, Sharma Y, Gupta S: Decellularized bovine placentome for portacavally-interposed heterotopic liver transplantation in rats. Mater Sci Eng C Mater Biol Appl 2019, 97: 293-301

10. DeTemple DE, Oldhafer F, Falk CS, Chen-Wacker C, Figueiredo C, Kleine M, Ramackers W, Timrott K, Lehner F, Klempnauer J, Bock M, Vondran FWR: Hepatocyte-induced CD4(+) T cell alloresponse is associated with major histocompatibility complex class II up-regulation on hepatocytes and suppressible by regulatory $\mathrm{T}$ cells. Liver Transpl 2018, 24:407-419

11. Wu YM, Joseph B, Gupta S: Immunosuppression using the mTOR inhibition mechanism affects replacement of rat liver with transplanted cells. Hepatology 2006, 44:410-419 
12. Sokhi RP, Rajvanshi P, Gupta S: Transplanted reporter cells help in defining onset of hepatocyte proliferation during the life of F344 rats. Am J Physiol Gastrointest Liver Physiol 2000, 279:G631-G640

13. Viswanathan P, Kapoor S, Kumaran V, Joseph B, Gupta S: Etanercept blocks inflammatory responses orchestrated by TNF-alpha to promote transplanted cell engraftment and proliferation in rat liver. Hepatology 2014, 60:1378-1388

14. Krohn N, Kapoor S, Enami Y, Follenzi A, Bandi S, Joseph B, Gupta S: Hepatocyte transplantation-induced liver inflammation is driven by cytokines-chemokines associated with neutrophils and Kupffer cells. Gastroenterology 2009, 136:1806-1817

15. Joseph B, Malhi H, Bhargava KK, Palestro CJ, McCuskey RS, Gupta S: Kupffer cells participate in early clearance of syngeneic hepatocytes transplanted in the rat liver. Gastroenterology 2002, 123: $1677-1685$

16. Viswanathan P, Gupta P, Kapoor S, Gupta S: Thalidomide promotes transplanted cell engraftment in the rat liver by modulating inflammation and endothelial integrity. J Hepatol 2016, 65:1171-1178

17. Malhi H, Gorla GR, Irani AN, Annamaneni P, Gupta S: Cell transplantation after oxidative hepatic preconditioning with radiation and ischemia-reperfusion leads to extensive liver repopulation. Proc Natl Acad Sci U S A 2002, 99:13114-13119

18. Malhi H, Annamaneni P, Slehria S, Joseph B, Bhargava KK, Palestro CJ, Novikoff PM, Gupta S: Cyclophosphamide disrupts hepatic sinusoidal endothelium and improves transplanted cell engraftment in rat liver. Hepatology 2002, 36:112-121

19. Gupta S, Rajvanshi P, Malhi H, Slehria S, Sokhi RP, Vasa SR, Dabeva M, Shafritz DA, Kerr: Cell transplantation causes loss of gap junctions and activates GGT expression permanently in host liver. Am J Physiol Gastrointest Liver Physiol 2000, 279:G815-G826

20. Benten D, Kumaran V, Joseph B, Schattenberg J, Popov Y, Schuppan D, Gupta S: Hepatocyte transplantation activates hepatic stellate cells with beneficial modulation of cell engraftment in the rat. Hepatology 2005, 42:1072-1081

21. Enami Y, Bandi S, Kapoor S, Krohn N, Joseph B, Gupta S: Hepatic stellate cells promote hepatocyte engraftment in rat liver after prostaglandin-endoperoxide synthase inhibition. Gastroenterology 2009, 136:2356-2364

22. Yadav N, Jaber FL, Sharma Y, Gupta P, Viswanathan P, Gupta S: Efficient reconstitution of hepatic microvasculature by endothelin receptor antagonism in liver sinusoidal endothelial cells. Hum Gene Therapy 2019, 30:365-377

23. Gorla GR, Malhi H, Gupta S: Polyploidy associated with oxidative injury attenuates proliferative potential of cells. J Cell Sci 2001, 114: $2943-2951$

24. Jaber FL, Sharma Y, Gupta S: Demonstrating potential of cell therapy for Wilson's disease with the Long-Evans cinnamon rat model. Methods Mol Biol 2017, 1506:161-178

25. Bahde R, Kapoor S, Viswanathan P, Spiegel HU, Gupta S: Endothelin-1 receptor A blocker darusentan decreases hepatic changes and improves liver repopulation after cell transplantation in rats. Hepatology 2014, 59:1107-1117

26. Bandi S, Tchaikovskaya T, Gupta S: Hepatic differentiation of human pluripotent stem cells by developmental stage-related metabolomics products. Differentiation 2019, 105:54-70

27. Bandi S, Gupta S, Tchaikovskaya T, Gupta S: Differentiation in stem/progenitor cells along fetal or adult hepatic stages requires transcriptional regulators independently of oscillations in microRNA expression. Exp Cell Res 2018, 370:1-12

28. Gupta S, Rajvanshi P, Sokhi R, Slehria S, Yam A, Kerr A, Novikoff PM: Entry and integration of transplanted hepatocytes in rat liver plates occur by disruption of hepatic sinusoidal endothelium. Hepatology 1999, 29:509-519

29. Bahde R, Kapoor S, Bandi S, Bhargava KK, Palestro CJ, Gupta S: Directly acting drugs prostacyclin or nitroglycerine and endothelin receptor blocker bosentan improve cell engraftment in rodent liver. Hepatology 2013, 57:320-330
30. Rajarathnam K, Schnoor M, Richardson RM, Rajagopal S: How do chemokines navigate neutrophils to the target site: dissecting the structural mechanisms and signaling pathways. Cell Sign 2019, 54: 69-80

31. Bhargava KK, Joseph B, Ananthanarayanan M, Balasubramaniyan N, Tronco GG, Palestro CJ, Gupta S: Adenosine triphosphate-binding cassette subfamily $\mathrm{C}$ member 2 is the major transporter of the hepatobiliary imaging agent (99m)Tc-mebrofenin. J Nucl Med 2009, 50: $1140-1146$

32. Joseph B, Bhargava KK, Tronco GG, Palestro CJ, Gupta S: Molecular pathway-specific 99mTc-N-(3-bromo-2,4,6-trimethyacetanilide) iminodiacetic acid liver imaging to assess innate immune responses induced by cell transplantation. Nucl Med Commun 2009, 30:126-133

33. Zerwes HG, Li J, Kovarik J, Streiff M, Hofmann M, Roth L, Luyten M, Pally C, Loewe RP, Wieczorek G, Banteli R, Thoma G, Luckow B: The chemokine receptor Cxcr3 is not essential for acute cardiac allograft rejection in mice and rats. Am J Transplant 2008, 8: $1604-1613$

34. Rosenblum JM, Zhang QW, Siu G, Collins TL, Sullivan T, Dairaghi DJ, Medina JC, Fairchild RL: CXCR3 antagonism impairs the development of donor-reactive, IFN-gamma-producing effectors and prolongs allograft survival. Transplantation 2009, 87:360-369

35. Tannapfel A, Geissler F, Witzigmann H, Hauss J, Wittekind C: Analysis of liver allograft rejection related genes using cDNA-microarrays in liver allograft specimen. Transplant Proc 2001, 33:3283-3284

36. Sreekumar R, Rasmussen DL, Wiesner RH, Charlton MR: Differential allograft gene expression in acute cellular rejection and recurrence of hepatitis C after liver transplantation. Liver Transpl 2002, 8:814-821

37. Sarwal M, Chua MS, Kambham N, Hsieh SC, Satterwhite T, Masek M, Salvatierra O Jr: Molecular heterogeneity in acute renal allograft rejection identified by DNA microarray profiling. N Engl J Med 2003, 349:125-138

38. Biton S, Ashkenazi A: NEMO and RIP1 control cell fate in response to extensive DNA damage via TNF-alpha feedforward signaling. Cell 2011, 145:92-103

39. Kapoor S, Berishvili E, Bandi S, Gupta S: Ischemic preconditioning affects long-term cell fate through DNA damage-related molecular signaling and altered proliferation. Am J Pathol 2014, 184:2779-2790

40. Bedke J, Nelson PJ, Kiss E, Muenchmeier N, Rek A, Behnes CL, Gretz N, Kungl AJ, Grone HJ: A novel CXCL8 protein-based antagonist in acute experimental renal allograft damage. Mol Immunol 2010, 47:1047-1057

41. Pawlick RL, Wink J, Pepper AR, Bruni A, Abualhassen N, Rafiei Y, Gala-Lopez B, Bral M, Shapiro AM: Reparixin, a CXCR1/2 inhibitor in islet allotransplantation. Islets 2016, 8:115-124

42. Hsu WT, Lin CH, Jui HY, Tseng YH, Shun CT, Hsu MC, Wu KK, Lee CM: CXCR4 antagonist reduced the incidence of acute rejection and controlled cardiac allograft vasculopathy in a swine heart transplant model receiving a mycophenolate-based immunosuppressive regimen. Transplantation 2018, 102:2002-2011

43. FrancoSalinas G, Mai HL, Jovanovic V, Moizant F, Vanhove B, Boeffard F, Usal C, Tak PP, Soulillou JP, Baeten D, Brouard S: TNF blockade abrogates the induction of T cell-dependent humoral responses in an allotransplantation model. J Leukoc Biol 2011, 90:367-375

44. Gerlach UA, Koch M, Muller HP, Veltzke-Schlieker W, Neuhaus P, Pascher A: Tumor necrosis factor alpha inhibitors as immunomodulatory antirejection agents after intestinal transplantation. Am J Transplant 2011, 11:1041-1050

45. Garrouste C, Anglicheau D, Kamar N, Bachelier C, Rivalan J, Pereira B, Caillard S, Aniort J, Gatault P, Soubrier M, Sayegh J, Colosio C, Buisson A, Thervet E, Bouvier N, Heng AE: Anti-TNFalpha therapy for chronic inflammatory disease in kidney transplant recipients: clinical outcomes. Medicine (Baltimore) 2016, 95:e5108

46. Miller KK, Wang D, Hu X, Hua X, Deuse T, Neofytou E, Renne T, Velden J, Reichenspurner H, Schrepfer S, Bernstein D: Thalidomide treatment prevents chronic graft rejection after aortic transplantation in rats - an experimental study. Transpl Int 2017, 30:1181-1189 